\title{
Comunicación

\section{La sexualidad femenina en discursos de la prensa popular y la ficción televisiva}

Female sexuality in discourses of popular press and TV fiction'

\author{
TANIA RODRÍGUEZ SALAZAR E \\ ILIANA PÉREZ SÁNCHEZ2
}

Este artículo presenta un análisis cul-

This paper shows a cultural analytural de discursos mediáticos provenientes de la autoayuda (revista Cosmopolitan) y de la ficción televisiva ("Las Aparicio"). Se exploran las formas en que abordan algunos temas de la sexualidad femenina y se destaca que fomentan un conjunto de significados y normas alternativas, pero acompañados de mensajes paradójicos y contradictorios que cuestionan su sentido liberador.

PALABRAS ClAVE: Revistas femeninas, sexualidad femenina, ficción televisiva, análisis cultural. sis of media discourses coming from self-help (Cosmopolitan) and TV fiction ("Las Aparicio"). We explore the ways they tackle some items of female sexuality and emphasize that they encourage a set of alternative significations and norms, but accompanied with paradoxical and contradictory messages that play down their liberator sense.

KEY WORDS: Women's magazines, female sexuality, TV fiction, cultural analysis.

1 Este artículo se realizó en el marco del proyecto "Hacia una sociología del amor" financiado por el Consejo Nacional de Ciencia y Tecnología con clave de registro 2008-01-103206.

2 Universidad de Guadalajara, México.

Correos electrónicos: tania.rs70@gmail.com; ilianaperez82@yahoo.com.mx Av. Parres Arias 150, Col. Belenes, C.P., 45100, Zapopan, Jalisco. México. 


\section{INTRODUCCIÓN}

En la época contemporánea en la que los medios de comunicación ocupan un papel central en la producción y circulación de significados sociales, las personas suelen vivir su sexualidad con la ayuda de la prensa, el cine, la televisión, y más recientemente, el ciberespacio. Este hecho ha motivado diversas investigaciones interesadas en valorar los modos en que las sexualidades son representadas en distintos productos mediáticos.

Quienes escribimos este artículo hemos hecho eco de dicho interés en investigaciones propias independientes. Iliana Pérez (2012) realizó un análisis sobre cómo una serie de ficción televisiva discurría sobre la sexualidad, mientras que Tania Rodríguez (2009) ha investigado la manera en que algunos artículos de autoayuda publicados en revistas femeninas abordan los temas del placer y la sexualidad. La representación de la sexualidad conlleva múltiples significados, con frecuencia contradictorios (McMahon, 1990), tanto en los productos mediáticos como en la vida cotidiana.

En este artículo nos hemos propuesto comparar nuestros principales resultados en torno a formas de representación mediática de la sexualidad, para valorar semejanzas y diferencias en los mensajes y las formas en que el discurso de autoayuda de la prensa popular converge con el discurso audiovisual de una serie de ficción, cuya trama central involucra posicionamientos frente a la sexualidad femenina. Sin importar sus diferentes lenguajes y géneros discursivos, tanto los textos escritos como las narrativas audiovisuales de ficción constituyen propuestas de sentido, o dicho de otro modo, configuran y hacen circular significados que revelan algunas de las preocupaciones femeninas contemporáneas. Ambos discursos están dotados por los autores y editores, o en su caso, por los guionistas y productores de un componente educativo. Tienen una pretensión aleccionadora sobre cómo comportarse sexualmente siendo mujer. Por otra parte, ambos productos mediáticos esbozan imágenes de feminidad que tienen alguna pretensión de ser alternativas: en ellos encontramos las resonancias de las voces del feminismo, así como de ideas postfeministas, aunque a modo de ideologías de consumo. Sin embargo, también observamos los sedimentos y reminiscencias 
de posturas tradicionales que refuerzan una cultura patriarcal. De aquí el interés en analizar los contenidos de estos mensajes culturales que pueden contribuir a otorgar visibilidad y normalizar nuevas prácticas y comportamientos sexuales de las mujeres, pero también a generar falsas impresiones de liberación femenina.

\section{LA SEXUALIDAD EN LA PRENSA POPULAR Y LA FICCIÓN TELEVISIVA}

Las formas de representar la experiencia sexual de la mujer en los medios de comunicación, y en particular en los que se analizan en este artículo, ha transitado por lugares opuestos: uno en el que se niega la sexualidad femenina, se privilegia la reproducción en detrimento del placer, el sexo de la mujer se subordina al hombre y se suele tipificar a la mujer como objeto sexual, y otro más libre o emancipado en el que la mujer es más activa sexualmente, en el que se le reivindica su derecho al placer y al erotismo, se favorece la desinhibición sexual y disminuyen las restricciones hacia sus expresiones sexuales. Diversas investigaciones nacionales e internacionales muestran estos resultados a partir del análisis de contenido, y en menor medida del análisis del discurso, en productos mediáticos particulares como series de ficción, telenovelas y contenidos editoriales y publicitarios de la prensa popular. En estos estudios sobresale un interés interdisciplinar por la construcción del género en las representaciones mediáticas. ${ }^{3}$ Enseguida veremos algunos resultados particulares.

Las revistas femeninas fueron uno de los primeros medios de comunicación que incorporaron contenidos editoriales sobre sexualidad de manera abierta y explícita, ampliando el rango de imágenes disponibles, abriendo fronteras sobre lo que antaño era considerado apropiado para cada género y dando importancia a la autoadministración de la sexualidad (McRobbie, 1999). No obstante, durante los siglos XX y XXI se ha abordado de modos ambivalentes la representación de la mujer y

3 Por ejemplo, Capdevila, Araüna y Tortajada (2011); Kim (2001); Lorié (2011); Machin y Thornborrow (2006); Mantilla (2007); McRobbie (1999); Rodríguez y El Jai (2010); Tyler (2004). 
la sexualidad femenina y se han creado estereotipos adaptados a la mujer que trabaja y goza de relativa independencia (véase Corona y De la Peza, 2007 para el caso mexicano). Por otra parte, algunas críticas provenientes de la investigación feminista anglosajona es que están contribuyendo a la colonización de la experiencia sexual. En estas revistas se manifiesta la pretensión de enseñar cómo desempeñarse sexualmente, cómo administrar el sexo y cómo trabajar en él para mejorarlo, limitando la libertad de las mujeres (Tyler, 2004). Otro aspecto importante es que la apertura editorial a contenidos sexuales tiene connotaciones comerciales. Estas revistas promueven la asociación entre el placer sexual de la mujer con la estética y la moda del cuerpo, particularmente en términos de su apariencia. Esta condición también puede ejercer presión y restringir a la mujer de diversos modos (Attwood, 2005).

Actualmente podemos observar estas tendencias también en las pantallas televisivas y en géneros que tradicionalmente evadían los temas sexuales o restringían su abordaje, como las telenovelas y las series. En sus representaciones de la sexualidad los melodramas mexicanos, aunque también de otras partes del mundo, tienden a censurar el erotismo y la sensualidad, al mismo tiempo en que asocian el sexo con la maldad y la perversión (Mazziotti, 2006; Orozco, 2006). Así mismo, tienden a supeditar el ejercicio de la sexualidad a la presencia de sentimientos amorosos y a relaciones de pareja legitimadas socialmente (Fernández \& Paxman, 2000; Gómez, 2005; Revilla, 2008).

Otros estudios sobre la sexualidad en la ficción analizan series que tuvieron la pretensión de introducir nuevas narrativas en torno a la sexualidad femenina. La serie "Sex and the City" (1998-2004) es una muestra de este tipo de narrativas que posteriormente será imitada por otras ficciones extranjeras. Cascajosa y Fernández (2008), Kim (2001) y Lorié (2011) coinciden en que esta ficción reveló una imagen inusitada de la experiencia sexual femenina; sin embargo, también transmitió nociones estereotipadas respecto del género femenino envueltas en concepciones modernas de empoderamiento.

Este tipo de series extranjeras estarían dando mayor visibilidad a la sexualidad femenina centrada en el placer, a la mujer como sujeto de deseo, en el marco de discursos feministas y postfeministas adaptados al mercado (Chicharro, 2013; Munshi, 2008). De modo que los dere- 
chos femeninos al placer sexual, al deseo, a tener un papel activo en la gestión de sus encuentros sexuales, se acompaña de exigencias de sexo glamoroso, de cuerpos esbeltos y cuidados que requieren lencería fina, ambientes de lujo y cenas románticas (Chicharro, 2013; McRobbie, 2004). En otros productos de ficción latinoamericanos la mayor presencia del erotismo femenino en las pantallas puede interpretarse en el sentido que la mujer continúa siendo representada como objeto sexual y se mantiene la tendencia mediática a explotar el cuerpo femenino (Capdevila et al., 2011).

\section{METOdOLOGÍA: CASOS, TEXTOS Y ESTRATEGIA DE ANÁLISIS}

Los mensajes de la prensa popular como de la ficción televisiva que aquí nos interesan hacen eco de la centralidad contemporánea de la sexualidad. Sus contenidos forman parte de ese giro público hacia la proliferación de discursos que promueven actitudes sexuales más permisivas, que otorgan legitimidad a una diversidad de valores, prácticas e identidades sexuales (Attwood, 2006). Enfatizan la sexualidad, sin importar sus diferencias en géneros discursivos y formatos mediáticos. Entendemos el discurso en su sentido más básico como "una configuración espacio-temporal de sentido". Esto significa que se trata de un registro material de procesos de producción de significados marcados por condiciones de producción y condiciones de reconocimiento (Verón, 1996). Con este antecedente, consideramos los discursos mediáticos como registros de significados que están marcados por lenguajes, códigos, lógicas de producción, así como por conocimientos socioculturales que les permiten a los receptores decodificar y crear sentido sobre lo que circula en tales discursos. Los productos mediáticos son productos culturales que se incorporan a las dinámicas socioculturales de significación en entornos locales y globales. De ahí el interés de profundizar en los significados que configuran en torno a temas socialmente relevantes como el género y la sexualidad, y en formatos de gran consumo como los que aquí interesan.

Los discursos o textos analizados provienen de una selección intencional en muestras de otros estudios (Pérez, 2012; Rodríguez, 2009) que abordan temáticas similares y que nos permitieron comparar los re- 
gistros de significados de estos dos géneros de comunicación mediática. Esta selección proviene de dos casos de estudio:

1. Cosmopolitan, publicación catorcenal de Televisa, ${ }^{4}$ editorial lanzada en el mercado mexicano desde 1973 en el clima de apertura sexual y liberación femenina iniciado a mediados de los años sesenta en México. Su contenido editorial se caracteriza por recurrentes abordajes de temas sexuales, por el uso de vocabulario sexual más o menos explícito y por la prevalencia de la autoayuda en este ámbito.

2. "Las Aparicio" (2010), serie producida por Argos Televisión para Cadena Tres. Según declaraciones de sus productores, se realizó con intenciones de trascender narrativas sexuales tradicionales. ${ }^{5}$ Es una serie por sus características formales, si bien su trama es típica de las telenovelas. Se transmitió solamente por televisión de paga en los meses de abril a octubre de 2010, pero actualmente también se pueden ver en Internet todos sus capítulos. ${ }^{6}$ La historia versa sobre las vidas íntimas de una familia integrada solo por mujeres: la madre y tres de sus hijas (Rafaela Aparicio y sus hijas Alma, Mercedes y Julia). El eje rector de la trama es la sexualidad femenina, cada uno de los personajes protagónicos representa facetas distintas de la mujer ante la experiencia sexual: el personaje de Alma simboliza a la mujer adulta liberada, empresaria en la industria del sexo, con alto nivel de escolaridad y que prefiere las relaciones casuales y $\sin$ compromisos de largo plazo; el personaje de Mercedes representa a la mujer adulta madre, profesionista y conservadora que encara una nueva condición de vida a partir de que se queda viuda; finalmente,

4 Televisa es una de las dos empresas mediáticas más poderosas de México que tiene estaciones de televisión y radio, satélites y redes, entre otras. Esta empresa produce y distribuye programas de televisión, películas, discos, revistas, periódicos, además de promover espectáculos deportivos y eventos especiales.

5 Las siguientes notas periodísticas muestran opiniones editoriales y declaraciones del productor Epigmenio Ibarra en este sentido (Cueva, 2010; Gil, 2010; “'Las Aparicio' hablarán sin tapujos en TV”, 2010).

6 www.argostv.com 
el personaje de Julia ejemplifica a la mujer abierta al sexo, que experimenta y prueba, y que busca definir su orientación sexual fuera de lo heterosexual.

En ambos casos se proyectan recomendaciones, consejos, ideales sobre cómo comportarse sexualmente ante ciertas circunstancias de modos implícitos o explícitos. Seleccionamos cuatro unidades de cada caso (artículos y segmentos narrativos) a partir del interés de comparar el abordaje de los siguientes temas, todos presentes, en al menos alguna parte de las muestras estudiadas: a) la gestión del placer y la preocupación por el desempeño sexual; b) la masturbación; c) la relación entre amor y sexo.

La selección de artículos de autoayuda en Cosmopolitan quedó conformada por los siguientes textos que se detallan con una interpretación de su contenido (véase Tabla 1).

\section{TABLA 1}

SELECCIÓN DE ARTÍCULOS DE AUTOAYUDA PUBLICADOS EN COSMOPOLITAN LATINOAMÉRICA, 2006

Títulos y descripción e interpretación breve del contenido

Artículo 1. Trucos de las diosas sexuales. A partir de una distinción entre "las mujeres que son buenas en la cama" y las "verdaderas diosas sexuales", el artículo configura un ideal de desempeño sexual basado en el aprendizaje de "trucos de seducción irresistibles" y en una "actitud entusiasta en la que casi todo está permitido" (mayo).

Artículo 2. No vuelvas a perder un orgasmo. En este texto se ofrece el "truco sexual" de la masturbación femenina cuando el "casi orgasmo" está en riesgo de esfumarse en una relación sexual. Este texto presupone que sus lectoras conocen y usan diferentes posiciones sexuales, que desean tener el máximo placer de todos sus encuentros sexuales y que están dispuestas a usar formas de estimulación y de placer complementarias a las que le ofrece su pareja (mayo). Artículo 3. ¿Lo amas o solo lo deseas? Este artículo pretende alertar o advertir a las lectoras de la confusión entre "pasión" y "amor verdadero". El mensaje se 
respalda en testimonios vivenciales de una chica a la que "el enamoramiento no le dura mucho" de modo que "un amor apasionado, termina relegado a la categoría de aventura sin mayor importancia". La idea central es que el amor es más que sexo, más que algo físico o el "simple deseo" (enero).

Artículo 4. Cosas que te quitan el sex appeal. Este artículo instruye sobre cómo manejar la sexualidad a partir de sancionar "conductas y gestos sutiles" que les restan sensualidad a las mujeres y que, por lo tanto, deben evitarse. En general, el artículo recomienda a la mujer no mostrarse en situaciones que le restan belleza o sensualidad, según testimonios masculinos que atestiguan con su experiencia que eso ocurre (abril).

Los segmentos narrativos seleccionados en la serie "Las Aparicio" corresponden a los siguientes capítulos y fragmentos narrativos (véase Tabla 2).

TABLA 2

SELECCIÓN DE SEGMENTOS NARRATIVOS

DE LA SERIE "LAS APARICIO”, 2010

Segmento narrativo y descripción e interpretación breve del contenido

Segmento 1. Alma tiene un encuentro sexual casual. En esta secuencia se observa que el personaje de Alma entra a un bar, aborda a un hombre, le invita una copa e inician una breve conversación (el propósito es tener un encuentro íntimo con el desconocido). Posteriormente ambos personajes tienen relaciones sexuales en la habitación de un hotel; ella es quien toma la iniciativa, dirige el encuentro y actúa de forma impositiva y un tanto agresiva (cap. 1).

Segmento 2. Alma se decepciona de su desempeño sexual. En esta escena, el personaje de Alma se encuentra con Leonardo (su novio) en la cama, sostienen un diálogo en el que ella a través de sus gestos, actitud y palabras, expone su decepción y molestia por no haber tenido un buen desempeño sexual. Leonardo intenta consolarla y bromea para restarle importancia a la situación (cap. 6).

Segmento 3. Julia habla de la masturbación. La escena transcurre en un entorno de diálogo informal, entre una tía (Julia) y su sobrina (Ileana) en el que la primera cuestiona a la segunda sobre sus necesidades de placer. La expectativa de Julia es que su sobrina atienda esos deseos, no solo con yoga, sino también con un poco de "autoservicio", término que emplea para referirse a la masturbación (cap. 33). 
Segmento 4. Mercedes es convenida a tener un encuentro sexual. Un conjunto de escenas exponen que los personajes de Alma y Julia presionan a su hermana Mercedes para que tenga relaciones sexuales con Claudio, quien es su socio en el trabajo. Al principio Mercedes se rehúsa; sin embargo, después admite que siente deseo por Claudio (a pesar de lo que lo categoriza así: "Es el típico macho mexicano que es misógino, que es tramposo, que maltrata a la mujer, que es súper coqueto ...”) y termina involucrándose sexual y sentimentalmente con él (caps. 42 y 52).

Como perspectiva de análisis recurrimos al análisis cultural del discurso $^{7}$ (D’Andrade, 2005; Hill, 2005; Quinn, 2005; Strauss, 2005) porque nos interesa descubrir representaciones, esquemas y modelos de carácter cultural que subyacen a los textos analizados más que los usos del lenguaje en sentido estricto, las condiciones de producción de estos discursos o su especificidad mediática. Con este propósito focalizamos la atención en algunos aspectos claves:

1. El vocabulario. Aquí identificamos algunos nombres empleados en los corpus analizados para denominar o evocar cuestiones sexuales: órganos, prácticas, posiciones, relaciones, principalmente. Específicamente nos interesaba identificar los usos de términos explícitos frente a los metafóricos o eufemísticos.

2. Las asociaciones conceptuales, valorativas, emocionales. En ese aspecto contemplamos las relaciones de oposición, complementariedad, jerarquía, que en los discursos analizados se establecían entre conceptos relevantes identificados de modo inductivo (amor/sexo; sexo en relación/sexo en solitario; sexo/orgasmo; sexo/consumo, sexo/ apariencia, comportamiento sexual femenino/comportamiento sexual masculino), así como las asociaciones valorativas y emocionales ligadas a dichos conceptos (sea a partir de identificar ideales, preferencias, a través de adjetivos, expresiones emocionales negativas o positivas).

7 Esta perspectiva de análisis proviene de la antropología cognitiva, específicamente de la teoría de los modelos culturales. Sus principales aportaciones son recursos para identificar, analizar, comparar, explicar modelos culturales subyacentes en diversas clases de discursos. 
3. Las evaluaciones narrativas implícitas o explícitas. Este aspecto se contempló en el análisis de las micronarraciones que conformaron el corpus de "Las Aparicio", y en menor medida, en los textos de autoayuda de Cosmopolitan (cuyo contenido narrativo es menor). Se analizaron los cambios de estado de los personajes para identificar los mensajes culturales de sus diálogos y las microhistorias de ficción de los segmentos contemplados en el corpus, pero también cómo los personajes, investidos de un rol sociocultural, evalúan implícita o explícitamente acciones, actores, medios y resultados implicados en tales episodios narrativos.

4. Las huellas de discursos sociales. En esta dimensión pusimos atención a las voces sociales que tenían alguna presencia en los corpus analizados. Observamos el vocabulario, el contenido de los mensajes culturales, para identificar las evocaciones parciales, implícitas o explícitas, de discursos ideológicos más amplios.

5. Los conflictos que pueden surgir entre los mismos. En esta dimensión intentamos rastrear los mensajes culturales en conflicto dentro de un mismo corpus, o entre los corpus analizados. Se buscaron ambivalencias, contradicciones, paradojas, en las formas de construir sentido sobre cuestiones sexuales.

Estas dimensiones de análisis nos permitieron observar distintas aristas de la construcción mediática (en prensa popular y ficción televisiva) de cada uno de los temas seleccionados para este artículo. Los resultados se exponen siguiendo los ejes temáticos que nos sirvieron para conformar una muestra, pero el análisis del abordaje de estos temas supuso la búsqueda, identificación, comparación e interpretación de los aspectos contemplados en las dimensiones de análisis brevemente expuestas y que no podemos presentar en toda su riqueza y extensión en el reducido espacio de un artículo de investigación.

LOS IMPERATIVOS SEXUALES:

FÍSICO, MENTAL Y TÉCNICO

De manera general observamos que ambos corpus analizados configuran una "obligación" femenina de tener sexo y de capacitarse para hacerlo 
de la mejor manera. ${ }^{8}$ Los mensajes de ambos discursos mediáticos, independientemente de los estilos y contenidos que expresan, recomiendan invertir recursos en sexualidad (tiempo, dinero, capacidades, aprendizajes, reflexión). El sexo se representa como una inversión necesaria para tener y conservar una pareja, al mismo tiempo que se muestra como una diversión o una actividad casual que produce placer. Las recomendaciones en aspectos de la sexualidad femenina van acompañadas de un fuerte espíritu comercial (Illouz, 1997; McRobbie, 2008).

Tanto en los artículos de autoayuda de Cosmopolitan como en las escenas de "Las Aparicio" se observan consejos e incitaciones dirigidas hacia las mujeres para que pongan atención, inviertan tiempo y trabajo personal en su vida sexual pues debe considerarse una prioridad.

En el caso de Cosmopolitan el consejo se produce a partir de recomendaciones sobre cómo dar y recibir placer (alcanzar el orgasmo, satisfacer a la pareja o incrementar el deseo) que se acompañan con ejemplos abundantes y detallados de experiencias sexuales que se pretenden universales, así como de citas de expertos (psicólogos, empresarias del sexo, terapeutas sexuales, autores de best sellers, entre otros); pero también a partir de que se configuran ideales como ser una "diosa sexual" o ser una mujer que "nunca pierde un orgasmo" o evita comportarse de modo no "sexy" (todos estos elementos aparecen desde los titulares de los artículos analizados).

En "Las Aparicio" esto ocurre cuando los personajes femeninos enfrentan una necesidad irremediable de sexo (segmento 1), dialogan sobre sexo o escenifican comportamientos sexuales (segmentos 3 y 4 ), cuando son objeto de críticas por la falta de sexo en su vida o autocríticas por un desempeño sexual no óptimo según criterios exigentes (segmento 2).

Tales formas de enfatizar la necesidad de atender la sexualidad propia convergen en crear imperativos sexuales para las mujeres que limitan su libertad y que pretenden tener un carácter universal e infalible (que se aplican a todas las mujeres en todas las circunstancias y nunca fallan).

8 Esto coincide con lo observado por Hoschchild (2003): que los expertos de la autoayuda se comportan como asesores bursátiles, recomendando dónde, cuánto y cómo invertir emocionalmente. 
De acuerdo con lo observado en los artículos de Cosmopolitan, los imperativos sexuales para las mujeres son de tres tipos: a) el imperativo físico que le exige cuidar la estética de su cuerpo, lucir "perfecta" y sexy, b) el imperativo mental que la obliga a estar dispuesta siempre y a gestionar en sí misma una actitud y estado de ánimo necesarios para los encuentros sexuales y c) un imperativo técnico a partir del cual se crea desconfianza en los modos espontáneos de obtener placer y se le fuerza a dominar estrategias de seducción, juegos, posiciones sexuales, y a mantener apertura a casi todo.

Estos tres tipos de exigencias para la sexualidad femenina también aparecen en las historias en que se involucran los personajes de "Las Aparicio". Las mujeres protagonistas de esta serie, con excepción de la madre cuya sexualidad casi no se aborda, son relativamente jóvenes, esbeltas y bellas, además de que suelen preocuparse por cuidar su apariencia. El segmento narrativo 4 ocurre justamente en una escena en la que los personajes femeninos están en una sesión de tratamientos de belleza (imperativo físico), la cual aprovechan para hablar de la falta de sexo de una de las hermanas. Ahí configuran también una supuesta obligación femenina de estar siempre dispuesta al sexo (imperativo mental) que las "expertas" ratifican cuando juzgan la sexualidad ajena. 9 En este fragmento narrativo las hermanas que juegan el rol de expertas en sexo (Alma y Julia), aconsejan e incitan al personaje conservador (Mercedes) para que tenga sexo con su socio (Claudio) con quien ha vivido subestimación y maltrato laboral. El consejo se respalda en el argumento de que la necesidad de placer es tan natural como la de "respirar" y que esto supone apertura y disposición.

Aquí queda muy claro que este imperativo de mentalidad abierta al sexo tiene un carácter paradójico: por una parte restituye el derecho de la mujer al placer, a su búsqueda abierta y sin restricciones, pero también contribuye a la creencia de que el valor y la felicidad de una mujer dependen de tener un hombre al cual "tirarse". El mensaje implícito es que una mujer sin sexo en relación es una mujer incompleta, a pesar de que se contradice el eslogan de la serie "Una mujer entera no nece-

9 Para un análisis del diálogo entre los personajes y la representación audiovisual, véase Pérez (2012, pp. 140-142). 
sita media naranja".10 De igual manera los diálogos de este segmento 4 construyen a Alma como la experta en sexo que puede pronunciarse sobre la sexualidad ajena, juzgar y recomendar de acuerdo con su propia sabiduría. La mujer que no tiene sexo o que tiene dificultades para tenerlo se ve obligada a defender el valor de su vida sin sexo. Esto se observa muy claro en la réplica que le hace Mercedes a su hermana:

Tú te las das de muy acá, porque tienes tu vida sexual perfectamente resuelta y estás en paz con ella. Oye ¡Dame chance! Ok, no por estar más o menos con mi sexualidad voy a tener una vida menos transparente que la tuya (segmento 4, cap. 42).

Respecto del imperativo técnico, observamos que los consejos sobre cómo dar o recibir placer siendo mujer privilegian las concepciones masculinas. En las recomendaciones escritas de la autoayuda o narradas dentro de la ficción audiovisual, se subordina la espontaneidad, la diversión y las sensaciones genuinas en pro de prescripciones técnicas de "expertos" que pretenden instruir a las audiencias sobre cómo comportarse en la intimidad. Los siguientes ejemplos provenientes del artículo "Trucos de las diosas sexuales" de Cosmopolitan son ilustrativos de este aspecto:

"Si él está sobre ti, tira de su pelo con una mano y aprieta su trasero. Si tú estás arriba, acaricia su pecho y besa su cuello"; "Frota la parte interna de tus muslos con lubricante, y deja que él deslice su miembro entre tus piernas antes de penetrarte. ¡Lo enloquecerás!”; "Mueve tu dedo en zigzag de arriba abajo sobre tus senos, o acaricia tu clítoris antes del clímax. 'Él sentirá que le das un show"' (artículo 1).

10 Este mismo segmento es destacado por Ramírez (2012), quien observa que los personajes recurren a la estrategia del cajoneo (meter en el cajón los aspectos negativos de la relación para no verlos y no darles importancia). La apelación a esta estrategia se manifiesta tanto en los consejos de las hermanas (Alma y Julia) para instigar un encuentro sexual con alguien con quien se ha vivido humillaciones, fraude, entre otras experiencias negativas; como en el acto de Mercedes de buscar el encuentro sexual por atracción dejando atrás lo negativo de otras áreas de su relación. 
La consigna para las mujeres en estos discursos mediáticos no solo se limita a demandar una vida sexual activa sino que también establece pautas específicas, y muy detalladas, en cuanto a las actitudes, habilidades, técnicas, atributos y conocimientos que debe tener la mujer para un encuentro placentero y exitoso. El placer es construido y definido mediante parámetros restringidos que indican qué es lo se debe considerar placentero en el nivel sexual, cuáles son las vías para acceder a dicho placer y quién tiene que sentir placer, ante qué "caricias" y con qué intensidad.

\section{LA GESTIÓN Y EL DESEMPEÑO SEXUAL}

Una recreación y desarrollo del ideal de "diosa sexual" que postula Cosmopolitan, es equiparable con el personaje de Alma de "Las Aparicio" que está configurado alrededor de la sexualidad de manera intensa: el sexo no solo es algo muy importante en su propia vida, sino que también trabaja para que las mujeres puedan disfrutar su vida sexual (imparte talleres y ofrece terapias para resolver problemas matrimoniales destinados a que las mujeres "descubran el placer" y se "reconcilien" con su sexualidad). Ella también es uno de los personajes que protagoniza escenas de empoderamiento femenino a través del sexo cuando gestiona encuentros sexuales ocasionales con habilidad y éxito, cuando actúa escenas sexuales en las que el hombre ocupa posiciones secundarias o de subordinación e incluso pondera críticamente su desempeño sexual y se avergüenza o decepciona de sí misma (segmentos 1 y 2 ).

Con Alma, los guionistas y productores de la serie representan a una mujer que sabe manejar el sexo con maestría, que suele tener éxito en sus encuentros sexuales y que se exige a sí misma un desempeño sexual de alto nivel. Esta representación de la amante perfecta, de la experta en sexo, establece que la mujer no puede darse el lujo de fallar en un encuentro sexual sin sentirse decepcionada. El mensaje general es que ya no solo los hombres deben sentirse avergonzados por un "pésimo desempeño sexual" sino también las mujeres, como si el asunto de la experiencia sexual fuera algo aislado completamente de la relación y de la situación en la que se produce el encuentro. 
Con la configuración de ideales rigurosos y restringidos de sexualidad femenina se les exige a las mujeres que su desempeño sea excelente en todos sus encuentros, al mismo tiempo que se categorizan ciertas rutinas sexuales como perfectas a partir de un solo indicador de eficiencia (el orgasmo), y se introduce el supuesto de que las mujeres deben estar atentas y evaluar permanentemente su propia actuación para mejorarla. Como lo plantea Attwood (2006), este rigor y control en las prácticas sexuales se instituye como un nuevo lineamiento y coloca a las mujeres como las responsables del éxito del intercambio íntimo y despoja a la experiencia sexual de la autonomía que debería caracterizarla. En lugar de ser un espacio de disfrute, el sexo queda sujeto a una escala valorativa. Con el constante autoescrutinio impuesto por el sexo postmoderno, los sujetos se enfrascan en una búsqueda interminable para tener "aptitudes" para el sexo.

Como hemos advertido, tanto los discursos de Cosmopolitan como de "Las Aparicio" instruyen cómo debe ser el comportamiento sexual de la mujer y suponen que el orgasmo es el único y gran indicador de eficiencia sexual. Así puede interpretarse el título y el contenido del artículo "No vuelvas a perder un orgasmo". Si se "pierde" alguna vez es porque se ha fallado en seguir los "trucos" adecuados que garantizan el buen desempeño y si se tiene éxito es porque la mujer conoce los pasos a seguir. Por otra parte, en "Las Aparicio" encontramos que el orgasmo se construye no solo como algo que se siente y se expresa, sino también como algo que debe acentuarse, mostrarse, dramatizarse para asegurar a su pareja el goce del momento. La representación audiovisual subraya que las mujeres exterioricen un éxtasis total. ${ }^{11}$

Otro rasgo que sobresale en cuanto a las técnicas de actuación sexual expuestas tanto en Cosmopolitan como en "Las Aparicio" es la inversión de roles sexuales para representar el tránsito de una sexualidad pasiva a una activa. Se construyen mujeres que imitan las necesidades eróticas y sexuales masculinas, que invierten los términos entre quien comienza o gestiona activamente el encuentro sexual y asignan

11 Ambas observaciones pueden interpretarse como un discurso de racionalidad organizacional (managerial discourse) en el que las relaciones eróticas se reducen a imperativos de desempeño (Tyler, 2004). 
a las mujeres estrategias de seducción, de gestión sexual, de comportamientos calculadores, coercitivos, culturalmente reservados para los hombres, en detrimento de otras formas de expresión sexual femeninas más libres, espontáneas y flexibles a las circunstancias y las situaciones de vida particulares.

En ambos corpus la mujer sexualmente activa se representa con restricciones y exigencias, pero también se prefigura asignándole esquemas de motivación y comportamiento típicamente masculinos. Las mujeres con una sexualidad abierta serían aquellas que tienen una necesidad de sexo irremediable al igual que los hombres (por lo que deberían estar abiertas al encuentro sexual de manera permanente, si no quieren que se le reste plenitud a su vida). Con esta representación no solo se refuerza el ideal cultural masculino de estar siempre dispuesto al sexo, en cualquier lugar y circunstancia, sino que también se configura un ideal casi idéntico para el género femenino. Las mujeres aparecen en los artículos de Cosmopolitan y en la serie "Las Aparicio" como obligadas a tener experiencias sexuales, a tener altas expectativas sobre su desempeño sexual, y a conceder en otros planos a cambio de sexo. La representación de la liberación sexual femenina termina siendo una mera apariencia, pues en el fondo se trata de una sexualidad orientada a los hombres. Nos presentan "una mujer tan hipersexual como un varón, siempre disponible, siempre orgásmica, jamás demandante, jamás emotiva. Una mujer a la que solo le interese el intercambio sexual como a los varones". 12

\section{EL PODER SEXUAL FEMENINO, EL SEXO EN RELACIÓN Y EN SOLITARIO}

Nuestros datos convergen con lo señalado por Machin y Thornborrow (2006) respecto de textos de revistas femeninas: construyen un mundo de poder sexual ficcional. En dicho mundo, el sexo es dramatizado, actuado e ilustrado, en una iconografía lingüística y visual común para representar el poder de las mujeres a través de la sexualidad. La mujer con poder es una mujer bella, esbelta, sensual, dispuesta al sexo y al placer,

12 Agradecemos estas palabras que nos permiten enfatizar nuestros resultados y que fueron sugeridas por un o una evaluadora anónima de este artículo. 
con trabajo y dinero. Contra los melodramas mexicanos tradicionales en los que la cultura de la pobreza se enaltece, en la historia de "Las Aparicio" casi no hay mujeres pobres porque los ideales de sexualidad femenina están fuertemente anclados al consumo. Las mujeres capaces de tener sexo sin ataduras de acuerdo a la trama son también mujeres con alto nivel adquisitivo, profesionales, independientes económicamente y con actividad empresarial. Al colocar la experiencia sexual en primer término se genera la noción de que es en el terreno sexual donde la mujer podrá sentirse realizada, en detrimento de otros ámbitos igualmente relevantes. Lo observado coincide con el señalamiento de Machin y Thornborrow (2006) de que el sexo ha sido fuertemente usado por los medios de comunicación para significar los valores centrales del poder y la libertad. Sin embargo, a través de este proceso otras formas de agencia femenina han quedado excluidas.

Más allá de la asociación conceptual entre buen sexo y consumo y las falsas impresiones de liberación sexual que promueven los textos mediáticos analizados, las representaciones del placer femenino casi siempre involucran relaciones heterosexuales y falocéntricas, en detrimento de otras posibilidades de obtención de placer sin el contacto con un hombre. Los textos mediáticos que hacen ecos del discurso liberal, postmoderno y cosmopolita reclaman principalmente que las mujeres tienen los mismos derechos sexuales que los hombres, así como que sus necesidades y deseos son similares (Inglis \& MacKeogh, 2012). Han logrado visibilizar reconocimiento de los derechos femeninos al disfrute y a la gestión sexual, pero también implican el riesgo expresado por Giddens (1992) de que el placer femenino se convierta en una exigencia que limita la libertad sexual de la mujer, o dicho de otro modo, que el goce se vuelva una imposición que pretenda circunscribir las sensaciones a ciertos principios.

En los artículos de Cosmopolitan como en las historias de "Las Aparicio" se pone el acento en la normalización del deseo y el placer femenino, al mismo tiempo, en que ciertas temáticas y prácticas inherentes a la vida sexual de las mujeres se omiten o se tratan con discreción. ${ }^{13}$

13 En el caso de "Las Aparicio", Pérez (2012) observó que eso ocurre con los temas de la menstruación, las prácticas sexuales durante el periodo 
Esto se observa en los textos mediáticos que aquí analizamos, en el caso particular de la masturbación, cuyo tratamiento es escaso y privilegia el sexo en relación y la heterosexualidad.

Este tema es abordado en el artículo "No vuelvas a perder un orgasmo" en el corpus de Cosmopolitan, que pretende convencer a las lectoras de que la "estimulación manual" es un recurso legítimo para garantizar el orgasmo. En el texto se construye la legitimidad de ese "truco sexual" planteando que si los hombres hacen cualquier cosa para satisfacerse sexualmente, las mujeres también pueden hacerlo. Se les recomienda a las lectoras masturbarse (con el eufemismo de la "estimulación manual") como un complemento para alcanzar el orgasmo cuando está a punto de "esfumarse" en una relación sexual con otro, aunque también se le hacen advertencias directas. La masturbación como complemento para alcanzar el orgasmo en pareja es un indicador de una concepción favorable a la sexualidad femenina activa. No obstante, la forma de referirse a esta práctica, así como las advertencias a las lectoras sobre los efectos negativos en su pareja si no utiliza con prudencia tal técnica de placer, vuelven ambiguo el mensaje hacia el activismo sexual de la mujer. Así mismo en este artículo se privilegia una concepción del sexo como una forma de relación, pues no se menciona la opción de considerarlo una manera de placer recreativo solitario o sin la necesidad de una pareja.

En "Las Aparicio" el mensaje es que la masturbación es una práctica normal y generalizada, así como una opción para las mujeres, especialmente para las jóvenes, pues representa una salida para liberar la tensión sexual (dramatizada como apremiante e incontrolable). No obstante también se categoriza como un género de actividad sexual de menor jerarquía que el sexo en relación pues se sugiere que no le proporciona a la mujer tanto placer como el propiciado por o compartido con los varones. La alusión a la masturbación en el corpus analizado ocurre en el segmento 3 cuando Julia invita a su joven sobrina a darse cuenta de que es sujeto de deseo y que el "autoservicio" es una forma de obtener placer. Esto puede interpretarse en el sentido de que el placer de la masturbación se considera más propio de las jóvenes que de las

menstrual o el embarazo, la sexualidad de las mujeres adultas mayores y la masturbación. 
mujeres maduras, pero también que el ideal de máximo placer es exclusivo del sexo en relación y depende comúnmente de tener a un hombre que lo propicie. El diálogo instaurado entre ellas refiere una representación de la práctica como algo que no puede satisfacer del todo a la mujer y lo podemos notar cuando Julia dice (cuestionando a su sobrina joven sobre sus deseos sexuales) "no hay una mujer en el mundo que no se haga un buen autoservicio de vez en cuando ...". Sin embargo, el diálogo culmina con un menosprecio de esta actividad sexual cuando Julia afirma dominar "el autoservicio", pero advierte que ella "necesita otra cosa, algo diferente ...". Por otra parte, también es interesante notar la omisión del tema de la masturbación en el segmento narrativo 4, en el que Mercedes es convenida a tener sexo con un hombre que no la ha tratado bien. Llama la atención que la recomendación de las hermanas "expertas" (Alma y Julia) vaya en el sentido de tener sexo con Claudio (minimizando la subestimación y el maltrato que vivió con él) para que Mercedes complete su vida y menos hacia buscar el placer de manera solitaria. La recomendación es "tírarselo" como una forma de satisfacer la necesidad biológica de sexo y placer, sin vislumbrar o imaginar una forma de recreación y placer sexual en solitario.

En ambos corpus la representación de la masturbación femenina tiende a naturalizar la idea de que el deseo sexual femenino se desencadena por la atracción hacia un hombre, como si el deseo no pudiera despertarse con otros estímulos. Adicionalmente, se configura como una práctica compensatoria en caso de no poder tener sexo en relación o una acción complementaria para garantizar el orgasmo, en detrimento de concepciones que la tipifican como una práctica independiente y como una vía, tan placentera como otras, para vivir y disfrutar la sexualidad.

Los mensajes de los textos analizados, en este sentido, no logran representar el sexo como una forma de placer recreativo, pues se continúa considerando primordialmente una forma de relacionarse con otro. Se tiende a menospreciar esta forma de placer femenino frente al placer que se obtiene en una relación sexual con otro, al mismo tiempo que se trata de un "truco" que debe administrarse con prudencia cuando se usa como complemento. Esto es importante si consideramos que como lo plantea Attwood (2005), un signo clave de la sexualidad femenina activa es justamente la masturbación. 


\section{LA ASOCIACIÓN/DISOCIACIÓN DEL AMOR Y EL SEXO}

La asociación o disociación del amor y el sexo es otro tema abordado por alguno de los textos analizados en ambos corpus. En Cosmopolitan el artículo “¿Lo amas o solo lo deseas?” crea una interrogante dirigida al yo, así como una serie de argumentos para asignarle una jerarquía ética mayor al amor sobre el sexo, y al sexo con amor respecto del mero sexo. En el mensaje de autoayuda se configura el amor como el depositario de múltiples experiencias positivas frente al deseo, además que se crea una asociación positiva entre amor y deseo para enarbolar un ideal de amor verdadero. Aquí algunas frases que muestran estas tendencias:

"El amor tiene muchos otros ingredientes que no tiene el deseo: admiración, ternura, respeto, necesidad de proteger y de ser protegidas ... Crece con la intimidad y con el conocimiento mutuo."; "eso hace que el amor sea infinitamente más difícil de experimentar, que el simple deseo."; "El amor sin deseo, está incompleto y siempre estará en riesgo, porque no es un AMOR DE VERDAD, así con mayúsculas" (artículo 3).

El mensaje de que el sexo es mejor con amor intenta ser subvertido en la serie "Las Aparicio", al menos en algunas de sus escenas, aunque la trama continúa en un sentido inverso. Un conjunto de escenas que nos permiten ilustrar cómo se intenta representar la disociación del amor y el sexo en el caso femenino se encuentra en el segmento 1. Ahí se representa la búsqueda femenina de sexo casual a través de un personaje: Alma sale a un bar en busca de sexo ocasional. Podemos notar que la estrategia de seducción reproduce casi en $100 \%$ el esquema de comportamiento masculino en tales ocasiones: ubicar un hombre solo, acercarse e invitar una copa, iniciar una conversación con datos falsos respecto de la identidad y lo que se hace (cambiarse el nombre, inventar actividades), manifestar la atracción sexual y buscar el encuentro íntimo. El encuentro sexual ocasional es todo un éxito, al grado que las artes sexuales de la protagonista son tan apreciadas por el amante efímero que termina buscando el teléfono como una forma de que lo ocasional se vuelva duradero. El esquema de seducción y la representación audiovisual de la gestión de sexo ocasional en este 
segmento narrativo convergen con lo observado por Machin y Thornborrow (2006) sobre que la agencia femenina sucede en el espacio de la fantasía, un espacio donde los obstáculos reales son eliminados y se tiende a teatralizar la experiencia sexual.

El mensaje detrás de esta escena es que las mujeres como los hombres pueden buscar sexo si así lo desean, que encontrar con quién tener sexo es algo fácil, basta con ir al lugar indicado y comenzar "la aventura". Para tener sexo no se tiene que tener una relación establecida, sino que se pueden gestionar los encuentros sexuales usando las estrategias adecuadas de búsqueda (ir al bar sola, arreglarse mucho, vestirse y comportarse de modo seductor). En esta escena podemos observar que se libera a la mujer de cualquier clase de prejuicios para buscar sexo ocasional, sin embargo, la trama no logra liberarla de los esquemas de comportamiento masculinos típicos para este tipo de encuentros.

La configuración de la escena, los diálogos, representan la conquista sexual como una salida a la rutina y una manera de incursionar al mundo del placer. En el sexo ocasional configurado en la serie, el valor del hombre se reduce a ser un instrumento de placer (un valor tradicionalmente asignado por los hombres a las mujeres y sujeto a la crítica feminista). Sin embargo, la representación de esta posibilidad de tener sexo ocasional sin mayores implicaciones no se logra a lo largo de la trama. Luego de este primer encuentro enmarcado en la mentira y en estrategias instrumentales para obtener placer, los personajes comienzan una relación afectiva. Si bien esta escena tipifica el derecho de la mujer al sexo ocasional, termina creando expectativas poco realistas respecto del porvenir de tales encuentros. En la historia de este personaje ese encuentro ocasional y pasajero se convierte en una historia de amor más o menos estable basada en compromisos. De modo que la configuración del personaje femenino capaz de tener relaciones sexuales sin conectarse emocionalmente queda trunca a partir de que se restituye el ideal de sexo con amor.

Cabe destacar que aunque en "Las Aparicio" se pretende representar la sexualidad disociada del amor, la propuesta no se completa pues los personajes femeninos terminan estableciendo vínculos amorosos con los hombres con quienes tuvieron intimidad en un primer momento solo por placer. 


\section{CONCLUSIONES}

Los discursos mediáticos analizados ofrecen a las mujeres una gama de tácticas y consejos para ser "buenas" amantes, todos enfocados a generar conductas más atrevidas o permisivas, a anhelar prácticas consideradas perfectas respecto del sexo para seducir a otro, alcanzar el orgasmo y conseguir niveles de deseo, excitación y placer de carácter excepcional con técnicas aparentemente universales. Todo esto se traduce, dicho metafóricamente, en dotar a la mujer de todo y el mejor equipo y armamento para las batallas del amor y del sexo.

Sin embargo, a pesar de las pretensiones de mostrar una sexualidad femenina distinta a la tradicional, los discursos analizados tienen un carácter paradójico. Las propuestas para vivir la sexualidad femenina a plenitud se ubican entre la promoción del hedonismo femenino para buscar, sentir, experimentar y gozar del sexo y las exigencias de convertirse en la "amante perfecta", la "diosa sexual" o la "experta en sexo" que pueda satisfacer los requerimientos, deseos y necesidades de uno mismo y del otro (a). ${ }^{14}$ Esto es paradójico, porque por un lado celebran el placer femenino, pero a su vez lo limitan y restringen con exigencias y parámetros aparentemente universales. Por otra parte encontramos tensiones entre dos grandes visiones sobre la sexualidad, una orientada al disfrute del yo y otra enfocada a complacer a otros. En muchas de las prescripciones sobre cómo comportarse sexualmente se tiende a privilegiar el prepararse para excitar, seducir y otorgar placer a otro, si bien no de manera exclusiva. También encontramos que ambos discursos coinciden en distinguir representaciones extremas sobre la sexualidad femenina: la de las amantes perfectas, que nunca fallan en alcanzar el orgasmo, que se permiten casi todo y que tienen una actitud siempre abierta al sexo, y que por lo tanto, se convierten en voces autorizadas para enseñar o criticar a otras mujeres, frente a las mujeres que no saben cómo ejercer su sexualidad, que tienen prejuicios para gozar y disfrutar,

14 De acuerdo con Attwood (2006) las exigencias sexuales para las mujeres encuentran correspondencia con el arquetipo de la nueva mujer, que está definida por ser urbana, glamorosa, fuerte y promiscua. Este modelo de mujer es considerado como la versión chic del postfeminismo. 
que desconocen las técnicas de seducción y placer, y que por lo tanto, requieren de instrucción y de un otro para sentirse completas o realizadas. Estas representaciones extremas dejan en penumbra los vaivenes de la vida sexual y la heterogeneidad de experiencias que pueden producir placer, así como las formas alternativas de gozar sexualmente sin la necesidad de una pareja.

A pesar de que ambos corpus tienen pretensiones de liberación, se continúa valorando más las relaciones sexuales en pareja que las experiencias de autoerotismo. Así se condiciona a la mujer a la figura masculina para la obtención del disfrute sexual, y se reproduce la imagen del hombre como el proveedor y el gestor del placer femenino. La masturbación es catalogada como algo accesorio, complementario, secundario, en el repertorio de comportamientos sexuales femeninos. Se le tiende a representar como un recurso disponible, mas no como una práctica consolidada para vivir y disfrutar la sexualidad.

Otra convergencia en los corpus analizados la encontramos en la representación del placer sexual como un ideal, como una experiencia magnificada, que se logra siguiendo técnicas sencillas de estimulación que pueden enseñarse y a las que se les adjudica un grado casi infalible de éxito o eficiencia. El poder de la mujer lo hacen recaer en su sensualidad, belleza, estilo, imagen o porte, pero sobre todo en su capacidad de emular las conductas sexuales masculinas.

Como vimos, los discursos mediáticos celebran el placer femenino, pero esta celebración se acompaña de nuevos imperativos físicos, mentales y técnicos en el ejercicio de la sexualidad. Estos imperativos paradójicamente limitan la libertad femenina, al mismo tiempo que eximen a la sexualidad de los componentes de la espontaneidad y la creatividad. Los mensajes aparentemente liberadores de estos medios de comunicación promueven la idea de que dar y obtener placer es algo altamente estandarizado (algo que se logra con técnicas de estimulación funcionales en todos los casos), en lugar de algo sumamente diverso y creativo. Por otra parte, la apertura editorial a contenidos sexuales no solo sirve para promover la liberación sexual femenina, sino también para la publicidad de productos que sostienen las industrias del sexo y la belleza. En algunos casos los abordajes mediáticos asociados al sexo tienen más una justificación comercial que de liberación. 
Finalmente ambos discursos mediáticos convergen en afirmar que la sexualidad de la mujer va unida a la presencia de sentimientos amorosos, y esto se promueve como la manera idónea de vivir la sexualidad. En este sentido es que podemos afirmar que se preserva el modelo de erotismo femenino ligado al amor señalado por Lipovetsky (2000), el cual se caracteriza por el hecho de que las mujeres siguen priorizando sus sentimientos, se aferran al ideal del amor romántico y no logran separar el sexo de sus afectos.

\section{Bibliografía}

Attwood, F. (2005). Fashion and passion: Marketing sex to women. Sexualities, 8 (4), 392-406.

Attwood, F. (2006). Sexed up: Theorizing the sexualization of culture. Sexualities, 9 (1), 77-94. doi: 10.1177/1363460706053336

Capdevila, A., Araüna, N. \& Tortajada, I. (2011, junio). Los roles de género, las relaciones de amor y de sexo en las series de ficción. El caso de "Sin tetas no hay paraíso". Quaderns del CAC 36, XIV (1), $67-74$

Cascajosa, C. \& Fernández, M. (2008). Género y estudios televisivos.

En I. Clúa (Comp.), Género y cultura popular (pp.177-226). Barcelona, España: Ediciones UAB.

Chicharro, M. (2013). Representaciones de la mujer en la ficción post-feminista: "Ally McBeal", "Sex and the City" y "Desperate Housewives". Papers, 98 (1), 11-31.

Corona, S. \& De la Peza, C. (2007). La liberación sexual en tensión: las revistas femeninas de los años 1970-1980. En S. Corona \& C. de la Peza (Coords.), Un siglo de educación sentimental. Los buzones amorosos en México (pp. 133-179). Guadalajara, México: Universidad de Guadalajara/Universidad Veracruzana/Universidad Autónoma Metropolitana-Iztapalapa.

Cueva, A. (19 de abril de 2010). La buena es "Las Aparicio". Milenio.

Recuperado el 18 de enero de 2011 de http://www.milenio.com/cdb/ doc/impreso/8753271

D'Andrade, R. (2005). Some methods for studying cultural cognitive structures. En N. Quinn (Ed.), Finding culture in talk. A collection of methods (pp. 83-104). Nueva York, EE.UU.: Palgrave Macmillan. 
Fernández, C. \& Paxman, A. (2000). El Tigre Emilio Azcárraga y su imperio Televisa. México: Grijalbo.

Giddens, A. (1992). La transformación de la intimidad. Sexualidad, amor y erotismo en las sociedades modernas. Madrid, España: Ediciones Cátedra.

Gil, I. (10 de mayo de 2010). Las Aparicio, ¿demasiado "progre” para México? Recuperado el 18 de enero de 2011 de http://www.bbc. co.uk/mundo/cultura_sociedad/2010/05/100528_0235_cultura_ mexico_telenovela_lasaparicio_jaw.shtml

Gómez, C. (2005). Cartografía de las telenovelas: por la ruta de la realidad de TV Azteca. Tesis de Maestría en Comunicación. Tlaquepaque, México: ITESO.

Heintz-Knowles, K. (1996). Sexual activity on daytime soap operas: A content analysis of five weeks of television programming. California, EE.UU.: Kaiser Family Foundation. Recuperado el 18 de enero de 2011 de http://www.kff.org

Hill, J. (2005). Finding culture in narrative. En N. Quinn (Ed.), Finding culture in talk. A collection of methods (pp. 157-202). Nueva York, EE.UU.: Palgrave Macmillan.

Hochschild, A. (2003). The commercialization of intimate life: Notes from home and work. California, EE.UU.: University of California Press.

Illouz, E. (1997). Consuming the romantic utopia: Love and the cultural contradictions of capitalism. California, EE.UU.: University of California Press.

Inglis, T. \& MacKeogh, C. (2012). The double bind. Women, honour and sexuality in contemporary Ireland. Media, Culture \& Society, $34,68-82$.

Kim, L. S. (2001). "Sex and the single girl" in postfeminism: The F word on television. Television \& New Media, 2 (4), 319-334.

"Las Aparicio" hablarán sin tapujos en TV. (18 de abril de 2010). El Informador. Recuperado el 18 de enero de 2011 de http://www. informador.com.mx/entretenimiento/2010/194586/6/las-apariciohablaran-sin-tapujos-en-tv.htm

Lipovetsky, G. (2000). La tercera mujer. Barcelona, España: Editorial Anagrama. 
Lorié, Á. F. (2011). Forbidden fruit or conventional apple pie? A look at "Sex and the City's" reversal of the female gender. Media, Culture \& Society, 33 (1), 35-51.

Machin, D. \& Thornborrow, J. (2003). Branding and discourse: The case of Cosmopolitan. Discourse \& Society, 14 (4), 453-471.

Machin, D. \& Thornborrow, J. (2006). Lifestyle and the depoliticization of agency: Sex as power in women's magazines. Social Semiotics, $16(1), 173-188$.

Machin, D. \& Van Leuwen, T. (2003). Global schemas and local discourses in Cosmopolitan. Journal of Sociolinguistics, 7 (4), 493-512.

Mantilla, L. (2007). El verdadero, el mejor amor. Experiencias e interpretaciones sobre el amor. En S. Corona \& C. de la Peza (Coords.), Un siglo de educación sentimental. Los buzones amorosos en México. Guadalajara, México: Universidad de Guadalajara/Universidad Veracruzana/Universidad Autónoma Metropolitana-Iztapalapa.

Mazziotti, N. (2006). Telenovela, industria y prácticas sociales. Colombia: Grupo Editorial Norma.

McMahon, K. (1990). The "Cosmopolitan" ideology and the management of desire. The Journal of Sex Research, 27 (3), 381-396.

McRobbie, A. (1999). In the culture society: Art, fashion and popular music. Londres, Inglaterra: Routledge.

McRobbie, A. (2004). Postfeminism and popular culture. Feminist Media Studies, 4 (3), 255-264.

McRobbie, A. (2008). Young women and consumer culture. Cultural Studies, 22 (5), 531-550.

Munshi, S. (2008). Chica -no siempre- interrumpida: Las mujeres en el cine de Bollywood y las series de televisión en India. Anuario Asia-Pacífico. Recuperado el 18 de enero de 2011 de http://www. anuarioasiapacifico.es/pdf/2008/sociedad3.pdf

Orozco, G. (2006, julio/diciembre). La telenovela en México: ¿de una expresión cultural a un simple producto para la mercadotecnia? Comunicación y Sociedad (nueva época), 6, 11-35.

Pérez, I. (2012). Representaciones de la sexualidad femenina en las narrativas televisivas. El caso de "Las Aparicio". Tesis de Maestría en Comunicación. Guadalajara, México: Universidad de Guadalajara. 
Quinn, N. (2005). How to reconstruct schemas people share, from what they say. En N. Quinn (Ed.), Finding culture in talk. A collection of methods (pp. 25-82). Nueva York, EE.UU.: Palgrave Macmillan.

Ramírez, R. (2012, enero/junio). Representación de las mujeres en la telenovela mexicana “Las Aparicio”. ¿Una mujer entera no necesita media naranja? Revista de Investigación en Ciencias Sociales y Humanidades (nueva época), 1 (1), 95-124.

Revilla, M. A. (2008). Representaciones de género: una mirada (más bien) conservadora. Mediaciones Sociales, (3), 199-217.

Rodríguez, T. (2009). El placer sexual en las revistas femeninas: entre la ficción y la realidad. Ponencia presentada en el Primer Coloquio de Investigación en Estudios Políticos y Sociales. Guadalajara, México: Universidad de Guadalajara.

Rodríguez, T. \& El Jai, T. (2010). Las revistas femeninas, la autoayuda y la sexualidad. En Z. Rodríguez (Coord.), Entretejidos comunicacionales. Aproximaciones a objetos y campos de la comunicación (pp. 229-264). Guadalajara, México: Universidad de Guadalajara.

Rodríguez-Morales, Z. (2007). Los buzones de la revista Cosmopolitan: mosaico del amor y la sexualidad moderna. En S. Corona y C. de la Peza (Coords.), Un siglo de educación sentimental. Los buzones amorosos en México (pp. 183-216). Guadalajara, México: Universidad de Guadalajara/Universidad Veracruzana/Universidad Autónoma Metropolitana-Iztapalapa.

Strauss, C. (2005). Analyzing discourse for cultural complexity. En N. Quinn (Ed.), Finding culture in talk. A collection of methods (pp. 203-242). Nueva York, EE.UU.: Palgrave Macmillan.

Tyler, M. (2004). Managing between the sheets: Lifestyle magazines and the management of sexuality in everyday life. Sexualities, 7 (1), 81-106.

Verón, E. (1996). La semiosis social: fragmentos de una teoría de la discursividad. Barcelona, España: Gedisa.

Fecha de recepción: 17/07/13. Aceptación: 27/08/13. 